\title{
Е.С. Шерстобитова
}

\section{ТВОРЧЕСТВО МАСТЕРА КНИЖНО-РУКОПИСНОГО ИСКУССТВА ГАВРИЛЫ (ИВАНА) БАСОВА (ПОСЛЕДНЯЯ ЧЕТВЕРТЬ XVI - ПЕРВАЯ ТРЕТЬ XVII В.) ${ }^{1}$}

\begin{abstract}
В статье представлена деятельность книгописиа и художника-знаменщика Гавриль (по прозвищу Иван) Басова. Выделяются этапы его творчества: жизнь и формирование в Твери, выполнение заказов с братьями Стефаном и Федором в Москве, развитие таланта и отличной от братьев манеры исполнения рукописных книг в мастерской при Троище-Сергиевом монастыре в 1608-1631 г2., где впоследствии он принял монашеский постриг, став иноком Гурием. Прослеживается стремление мастера отойти от черно-белого старопечатного стиля орнамента к декоративности, достигнутой через применение цвета и золота. Изменения затронули не только художественное оформление книг, но и манеру письма.

Ключевые слова: древнерусские рукописи, старопечатный орнамент, Гаврила (Иван) Басов.
\end{abstract}

Трудности исследования творческой судьбы Гаврилы-Ивана Басова связаны с разрозненностью сведений о нем. В трудах середины XIX - середины $\mathrm{XX}$ в., посвященных древнерусскому искусству, упоминается иконописец меньшей статьи Иван Басов [1. С. 12], он же отмечен как расписавший собор Рождества Богородицы в Саввино-Сторожевском монастыре в 1650 г. [2. C. 21], как знаменщик Троице-Сергиевой лавры Ивашко Сергеев Басов [3. С. 120] и как Иван Басов, написавший и украсивший в Твери Евангелие [4. С. 158]. В 1962 г. в «Словаре русской, украинской, белорусской письменности и литературы до XVIII века» появляются упоминания о художнике как о двух мастерах. В первом он назван как «Гаврило Басов, „прозванием Иванко“, „сколасник, рекше ученик“, писец и иллюстратор житий Зосимы и Савватия Соловецких в 1623 г. и Пролога годового в XVII в.», во втором «Басов Гавр[ила] Серг[еев], москвич, писец Псалтыри следованной в 1585/1586 г.» [5. С. 26]. В 1974 г. Т.В. Диановой была предпринята первая попытка установить некоторую взаимосвязь между этими именами. Рассмотрев московские рукописи Гаврилы Сергеева сына Басова Псалтырь следованную [6] и Сборник богослужебный ${ }^{2}$ [7], исследовательница сравнила их с книгой Евангелие [8], написанной в Твери Иваном Сергеевым Басовым. Обнаружив различие в почерках, она предположила, что писцы были братьями [9. С. 325, 327]. Она также атрибутировала мастеру написание Оглавления на 6 вставных листах Служебника [10] XV-XVI вв. [Там же. С. 323].

Лишь недавно выявленные Т.В. Анисимовой новые рукописи, исполненные братьями Басовыми, позволили утверждать, что здесь перед нами один

\footnotetext{
${ }^{1}$ Статья выполнена при поддержке Правительства РФ (Постановление № 211 от 16.03.2013 г.), соглашение № 02.А03.21.0011.

${ }^{2}$ Книга названа Т.В. Анисимовой «Архиерейский чиновник» и атрибутирована Федору Басову, брату Гаврилы. См.: [11. С. 605].
} 
мастер - книгописец и художник-знаменщик Гаврила (Иван) Сергеев Басов $[11,12]$. Н.П. Парфентьев предположил, что Иваном (Ивашкой, Иванкой), именем, данным ему при рождении и после крещения ставшим прозвищем, Гаврилу (Гавриила) Басова называли в семье и родном городе Твери [13. C. 24].

В период творческого становления братья Стефан, Федор и Гаврила Басовы обучались, вероятно, совместно, используя для овладения навыками первопечатные книги 1550-1570-х гг. ${ }^{1}$ В обучении письму наиболее тесная связь у Гаврилы обнаруживается со Стефаном, который, возможно, был старшим из братьев и оказал на Гаврилу более сильное влияние, чем Федор (почерки братьев схожи между собой, что неоднократно отмечалось исследователями).

Ранние исполненные Гаврилой рукописи были созданы им в середине 1580-х гг. для московских жителей. В это время братья Басовы жили в Москве. Возможно, там они создали артель по переписке книг [14. С. 48].

Одним из первых заказов Гаврилы стала рукопись Псалтырь с восследованием [6]. Из послесловия (л. 325, 325 об.), написанного по образцу послесловия Петра Мстиславца к Евангелию 1575 г., известно, что книга создавалась для Деомида Дементьева Гаврилой (там же в другом написании «Гавриилом») Сергеевым сыном Басовым в 1585-1586 гг. По предположению Н.П. Парфентьева, послесловие от имени Гаврилы и большую часть рукописи написал Стефан. Изучив, как меняется полууставное письмо книги, исследователь предположил, что Гаврила переписал только л. 1-48 [14. С. 48]. Согласно анализу Н.П. Парфентьева, в начале рукописи книгописец старался приблизить свое написание к более вертикальному и компактному почерку протографа. Однако вскоре его письмо стало «более твердым и небрежным» и перешло «в собственный почерк мастера» [13. С. 25]. Т.В. Анисимова же отметила, что на л. 1-48 буквы более вытянутые, «прижаты» друг к другу. Но она не исключает вариативность почерка Гаврилы на протяжении всей книги [11. С. 602]. Декоративное оформление книги Н.П. Парфентьев атрибутировал Федору. Однако Гавриле, вероятно, принадлежит создание раскрашенной, с золотом, заставки на л. 3 [13. С. 26]. Она выделяется среди других изображений рукописи. Т.В. Дианова, заметив это отличие, предполагала, что заставка исполнена в более поздний период [9. С. 325].

В 1586 г. (до октября) Гаврила вместе с братом Федором участвовал в создании художественного облика переписанной Стефаном рукописи Мерило праведное [15], заказ на которую был получен от Митрополита всея Руси Дионисия. Н.П. Парфентьев, сравнив декоративное убранство этой книги с более поздними исполненными Гаврилой Басовым рукописями, полагает, что художнику-знаменщику принадлежит здесь создание или раскраска нововизантийского орнамента с небольшими вкраплениями старопечатного стиля на титульном листе, а также украшения в цвете с золотом на л. 4 (малая заставка

\footnotetext{
${ }^{1}$ Как показали исследования Т.В. Анисимовой и Н.П. Парфентьева, художественными образцами декоративного оформления исполненных впоследствии братьями Басовыми рукописей стали книги: Апостол Ивана Фёдорова 1564 г. и Евангелие «анонимной» типографии, опубликованное около 1555 г., а образцом для Послесловий служило Послесловие Петра Мстиславца к Евангелию 1575. См.: $[11,19]$.
} 
и полевой цветок в старопечатном стиле) и л. 7 (большая заставка в сочетании старопечатного и нововизантийского стилей) [13. С. 27].

Следующая книга Гаврилы Басова - Евангелие тетр [8. Л. 526] - создавалась уже не в Москве, хотя в целом в ней отражены те же сложившиеся к этому времени в искусстве мастера особенности письма и оформления рукописей. Из послесловия мы узнаем, что рукопись переписана в 1593-1595 гг. в Твери. Книгописец «Иван» Сергеев сын Басов указал, что «под своим кровом близ дому своего» он выполнял заказ тверского жителя И.Г. Репьева для местной церкви Иокима и Анны и пророка Ильи при тверском архиепископе Захарии. Т.В. Анисимова предположила, что заказчиком рукописи был князь Иван Григорьевич Репнин [11. С. 606]. Но Н.П. Парфентьев не обнаружил такое имя у представителей родословной Репниных и, кроме того, считает, что писец обязательно упомянул бы высокий чин заказчика [13. С. 23]. Рукопись написана крупным полууставом. Т.В. Анисимова полагает, что художественным образцом для изображения евангелистов стало Евангелие Петра Мстиславца 1575 г. [11. С. 606]. Однако, по мнению Н.П. Парфентьева, изображение евангелиста Матфея (л. 9 об.) отсылает к гравюре царя Давида из Псалтыри Петра Мстиславца 1576 г., элементы интерьеров миниатюр с Марком и Лукой (л. 148 об., 237 об.) срисовывались мастером с различных книг, а изображение с евангелистом Иоанном (л. 381 об.) близко к иконописной прориси [13. С. 24-25]. В этой рукописи также присутствует художественное стремление Гаврилы обогатить орнаментику книги цветом, хотя пока на данном этапе оно выражено неярко.

Новые сведения о жизни Гаврилы Басова относятся уже к Смутному времени - к 1608 г. - и связаны с созданием им рукописи Евангелие для казначея Троице-Сергиева монастыря Иосифа Девочкина, о чем сообщается в послесловии (л. 384). В этой книге мастер называет два своих имени: «грешный Гаврилка, сын Сергея, Басов по прозвищу Ивашко». Книга написана полууставом с применением киновари и золота. Ее художественное оформление отличается от предыдущих рукописей пышностью орнаментики (16 украшений, 11 заставок, 4 - на титульных листах с большими художественно проработанными буквицами, а также декоративные поля, окрашенные в оттенки зеленого, оранжевого и серого). На трех листах Евангелия в своей иконографии имеются изображения евангелистов: Матфея (л. 13), Луки (л. 18), Иоанна (л. 286) $)^{1}$.

После работы над этой рукописью снова сведения о творчестве Гаврилы Басова прерываются, однако все последующие книги, созданные при его участии, будут связаны с Троице-Сергиевым монастырем, а декоративное оформление рукописей близко по исполнению к предыдущему произведению.

В 1618 г. - мае 1619 г. Гаврила работал над объемной книгой (более 900 листов) Псалтырь с восследованием [16] для келаря Троице-Сергиева монастыря Авраамия Палицына. Б.М. Клосс полагает, что рукопись переписана монахом клириком Кириллом Новгородцем при участии Гаврилы [17. С. 103]. Однако сведения книжных описей за 1701 г. [18. Л. 258 об.] и 1723 г. [19. Л. 21 об.] указывают на письмо Ивана Басова. Художественный облик

\footnotetext{
${ }^{1}$ Книга выставлялась на аукционе Сотбис. См.: [40].
} 
книги представлен 52 красочными заставками, украшениями полей, большими буквицами, инициалами, написанными киноварью, с золотом, применением написанной золотом вязи, а также миниатюрой, изображающей царя Давида, возможно, созданной при участии брата Федора, который числился в 1613-1615 гг. знаменщиком Оружейной палаты [13. С. 37].

Б.М. Клосс указал, что в это же время, в конце 1618 - начале 1619 г., Гаврила украшал рукопись «Сказание об осаде Троице-Сергиева монастыря (1608-1610 гг.)» [20] Авраамия Палицына, переписанную, по его мнению,

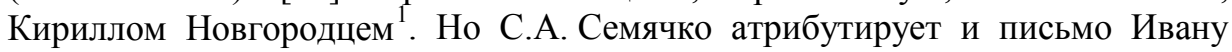
Басову [21. С. 408].

Из записей писцовых книг за 1623-1624 гг. известно, что в ту пору знаменщик Ивашко Сергеев Басов проживал в «нетяглой» слободе с. Клементьева среди мастеровых людей, получавших от Троице-Сергиева монастыря за свой труд денежное и хлебное жалование [3. С. 120].

Согласно атрибуции Н.П. Парфентьева, в этот период - между 16191624 гг. - Гаврила украшал рукопись Стихирарь певческий (л. 7, 351, 487) [22], написанную Логином Шишеловым, который при Троице-Сергиевом монастыре служил в то же время уставщиком, головщиком монастырского хора, мастером-распевщиком. Особо выделяется первый, титульный, лист с изображениями «ветвей-цветов» [23. С. 53].

Но, пожалуй, наиболее встречаемой книгой в исследованиях творчества Гаврилы Басова стала рукопись, созданная в 1623 г., - Житие и подвиги преподобных Зосимы и Савватия Соловецких [24]. Ее заказчиком был келарь Троице-Сергиева монастыря Александр Булатников, который в послесловии рукописи (л. 272-273) сообщил, что эта роскошная книга предназначалась им для Соловецкой обители, где он был пострижеником. А. Булатников обратился к патриарху Филарету, приславшему затем лицевой список книги конца XVI в., исполненный царскими иконописцами. Он стал образцом для писавших и украшавших рукопись 1623 г. мастеров, среди которых был «мало ученый в разуме, явный грешник и оставленый бедник Гаврила прозванием Иванка Басов, сколастик, рекше ученик», пребывающий «в чину учащихся» для постижения «Божественых писаний» (л. 275-276). Мастер согласно написанному им второму послесловию к книге «потрудился в чернильном писании и в золотном, и в заставицах». Н.П. Парфентьев полагает, что Гаврила работал над текстом рукописи, вписывал надписи и заголовки золотом или киноварью в миниатюры. Его манере близки также исполненные в книге заставки, украшения. Однако высокий уровень исполнения рисунков 235 миниатюрных изображений о жизни преподобных Зосимы и Савватия свидетельствует о таланте неизвестного нам царского знаменщика, чьей руке, очевидно, принадлежит их создание, который был прислан Филаретом, о чем также в послесловии сообщил А. Булатников [13. С. 38].

Вероятно, еще в начале XVII в. Гаврила приступил к созданию книги Служебник с Требником [25], над которой продолжил работать после перерыва «спустя 15-20 лет» [12. С. 273]. Это предположение, сделанное Т.В. Анисимовой, было обосновано Н.П. Парфентьевым в ходе изучения

${ }^{1}$ Б.М. Клосс сравнил художественное оформление этой рукописи с украшением Жития Зосимы и Савватия Соловецких [24. Л. 18] и Апостола, переписанного Кириллом Новгородцем [41. Л. 35]. См.: [27. С. 9]. 
имеющей различные филиграни бумаги, на которой написана книга, особенностей почерка писца и художественного оформления. Н.П. Парфентьев заметил, что в письме начала XVII в. преобладал «ровный», «даже несколько изящный» почерк. С л. 204 он чередуется с «небрежным», «более подходящим для черновиков». Сравнение исполненных 10 заставок рукописи показало, что время их исполнения также различно. Заставка на титульном листе (л. 10) более поздняя. 2 заставки - оттиски, причем одна из них без цветовой доработки. Вероятно, для них Гаврила Басов использовал старые печатные доски, применявшиеся в Минее общей в 1600 г. Андроником Невежей. Учитывая связь Федора Басова с Московским печатным двором и Иваном Невежиным, можно предположить, что именно через брата они стали доступны Гавриле [13. С. 38-39].

Эта рукопись, исходя из записей на л. 1-23, принадлежала архимандриту Троице-Сергиева монастыря Дионисию Зобниновскому, для которого Гаврила Басов создавал примерно в середине 1620-х гг. и следующую большую книгу (более 1000 листов) - Псалтырь с восследованием и Уставом [26]. Из книжной описи 1701 г. известно, что в ней «писмо Феодора да Ивана Басова» [18. Л. 258 об.]. Почерком Гаврилы, как установил Н.П. Парфентьев, написаны отдельные части книги (л. 1-12, 228-419 об., 797 об. - 874 об, 929-1098) [13. С. 39]. Б.М. Клосс указывает на участие в написании рукописи Кирилла Новгородца [27. С. 7; 17. С. 103, 106]. Книга содержит украшения: 25 заставок, инициалы, исполненные киноварью, и в старопечатном стиле.

Та же книжная опись называет еще одну рукопись Гаврилы 16201630-х гг. - Апокалипсис толковый с Житиями [28], но в ней отсутствуют признаки работы мастера.

Б.М. Клосс полагает, что Гаврилой исполнены вкладная запись (л. 424) и записи по нижнему полю листов в переписанной для Александра Булатникова в 1626 г. Кириллом Новгородцем рукописи Толкования Феофилакта Болгарского на Евангелия Матфея и Марка [29]. Также исследователь определил почерки этих мастеров в другой книге: Гаврила переписал книгу Толкование Феофилакта Болгарского на Евангелие от Иоанна [30], а Кирилл в ней исполнил вкладную и по нижнему полю листов записи [27. С. 8]. Однако C.А. Семячко атрибутировала обе эти рукописи перу Гаврилы, как и названное Б.М. Клоссом Евангелие от Луки [31], отнесенное им письму Кирилла Новгородца [21. С. 408].

Возможно, одной из последних исполненных Гаврилой книг стала рукопись Пролог в двух полугодовых частях. На сегодняшний день ученые [27. С. 8 ; 12. С. 274; 13. С. 40] исследовали второй том - на сентябрь - февраль [32]. Из послесловия заказчика и вкладной записи рукописи ${ }^{1}$ известно, что над книгой мастер «Гаврила Басов, прозванием Иванка», работал с 1630 г. до 1 марта 1631 г. Как и рукопись Житие и подвиги преподобных Зосимы и Савватия Соловецких, она была заказана А. Булатниковым для вклада в Соловецкий монастырь. Рукопись содержит послесловие заказчика, написанное рукой Гаврилы, а также послесловие самого книгописца (л. 539-539 об.), в котором он сообщает о своем иноческом имени, посвящении в сан дьякона и

${ }^{1}$ Б.М. Клосс полагает, что вкладная запись по нижнему полю (л. 1, 99, 198, 286, 379, 468) выполнена Кириллом Новгородцем. См.: [27. С. 8]. 
проделанной работе: «...Божиею милостию написана бысть сия святаа книга Пролог на две части, месяц март и месяц сентябрь, послужением и потружением в чернилном писании и в прочих тоя же пречестныя обители Живоначалныя Троица смиреннаго диакона инока Гуриа, в мирских же прибывающаго... многогрешнаго Гаврила Басова, прозванием Иванка». Имеются отличительные особенности художественного оформления книги: яркость и украшения на полях, увенчанные «золотыми „флюгерами“, в том числе в виде двуглавого орла» [13. С. 40].

Б.М. Клосс считает, что Гавриле принадлежит украшение второй части рукописи Пролога на мартовскую половину года [33], переписанной Кириллом Новгородцем [27. С. 8]. С.А. Семячко опровергает участие в создании книги Кирилла, полагая, что оба тома переписаны и украшены Гаврилой, на что мастер сам указал в его вышеприведенной записи сентябрьского тома [21. C. 406].

Исследователь также предположила, что почерком Гаврилы были выполнены вкладные записи, «особенно записи на л. ІІ» в сентябрьском томе еще одного Пролога [34], переписанного, по ее предположению, Кириллом Новгородцем для А. Булатникова (рукопись было вложена в Соловецкий монастырь в 1633 г.) $)^{1}$ [21. С. 408].

С.А. Семячко атрибутировала Гавриле еще три рукописи (на основе изучения «почерка; определенного набора текстов, сделавшего возможным сопоставление этих рукописей по составу; манеры оформлять сборники с помощью предисловия к оглавлению; а в рукописи Солов. 587/606 и использованной бумаги») [21. С. 409]: Следованную псалтирь [35], сборник [36] и Часослов [37]. Также исследователь полагает, что Гаврила сделал вкладные записи в книгах ГИМ. СИН. 335 [38] и РНБ. Сол. № 881/991 [39].

За продолжительное время, проведенное при монастыре, Гаврила создавал рукописи, отличающиеся богатым орнаментальным убранством. В это время от работал с братом Федором, писцом Логином Шишеловым, возможно, с Кириллом Новгородцем, создавая книги для выдающихся лиц ТроицеСергиевой обители (казначея Иосифа Девочкина, архимандрита Дионисия Зобниновского, келарей Александра Булатникова и Авраамия Палицына).

И.Е. Забелин указал, что в 1650 г. некий Иван Басов был кормовым иконописцем меньшей статьи [1. С. 12]. Имеются сведения и об Иване Басове, расписывающем в том же году собор Рождества Богородицы в СаввиноСторожевском монастыре [2. С. 21]. Но относятся ли эти сведения к творчеству книгописца и художника-знаменщика Гаврилы (по прозвищу Ивана) Басова, еще требуется уточнить. К тому же к этому времени при постриге он получил имя «смиреннаго диакона инока Гурия».

Орнаментальное творчество Гаврилы (Ивана) Сергеева Басова, как и его братьев Стефана и Федора, формировалось под влиянием книжно-рукописной традиции старопечатного стиля. Копируя и перерабатывая искусство первопечатных книг, постепенно Гаврила выработал собственную манеру, формирование которой связано с обстоятельствами творческой биографии мастера. Деятельность художника, вероятно, охватывает 1580-1630-е гг. Вы-

1 Б.М. Клосс атрибутировал написание книги ему неизвестному писцу, а вкладные записи - Кириллу Новгородцу [27. С. 8]. 
является несколько этапов его творческого пути. Первый был связан с работой в Москве совместно с братьями Стефаном и Федором. Уже тогда проявляется характерная черта его творческого почерка - стремление к цвету и декоративности, что отличает его манеру от особенностей искусства братьев. В дальнейшем эта особенность проявит себя на более высоком уровне мастерства. После этого Гаврила некоторое время пребывает в родной Твери и работает там. С 1608 г. начинается наиболее плодотворный этап его творчества, связанный с Троице-Сергиевым монастырем. Именно здесь завершается формирование его манеры художественного оформления книг и наступает расцвет творчества. Его искусство, отвечающее вкусам заказчиков, представляло собой декоративный вариант старопечатного стиля орнаментики. По мнению Н.П. Парфентьева, на формирование авторского художественного стиля Гаврилы оказали влияние востребованность и поощрение яркого расцвечивания украшений старопечатного орнамента в Троице-Сергиевом монастыре [13. С. 40]. Его творческий метод введения цвета усилил орнаментальность заставок и украшений, позволил выработать мастеру авторское своеобразие. Старопечатный орнаментальный стиль при этом трансформировался в его искусстве в более декоративный. Почерк также менялся на протяжении этих периодов в зависимости от размера рукописи, заказчиков. Благодаря исследователям творчества Гаврилы Басова и его братьев (выявлению рукописей, атрибутированию книг) появилась возможность изучить в дальнейшем искусство художника-знаменщика с искусствоведческих позиций более детально.

\section{Литература}

1. Забелин И.Е. Материалы для истории русской иконописи // ВОИДР. М., 1850. С. 1-128.

2. Успенский А.И. Царские иконописцы и живописцы XVII века : словарь. М., 1910. Т. 2. $402 \mathrm{c}$.

3. Арсений, иером. Исторические сведения об иконописании в Троицкой Сергиевой Лавре // Сборник на 1873 г., изданный Обществом древнерусского искусства при Московском публичном музее. М., 1873. С. 119-133.

4. Сидоров А.А. Древнерусская книжная гравюра. М. : Изд-во АН СССР, 1951. 396 с.

5. Будовнии И.У. Словарь русской, украинской, белорусской письменности и литературы до XVIII века / отв. ред. Д.С. Лихачев. М. : Изд-во АН СССР, 1962. 398 с.

6. ГИМ. Щук. 30.

7. ГИМ. Щук. 563.

8. ГИМ. Муз. 3441.

9. Дианова Т.В. Старопечатный орнамент // Древнерусское искусство. М., 1974. С. 296334.

10. ГИМ. Син. 268.

11. Анисимова T.B. Рукописи московских писцов братьев Басовых (80-е годы XVI - начало XVII в.) // От Средневековья к Новому времени : сб. статей в честь О.А. Белобровой. М., 2006. C. $587-608$.

12. Анисимова Т.В. О новонайденных рукописях строгановских писцов братьев Басовых // История библиотек. Исследования, материалы, документы : сб. науч. статей. СПб.: РНБ, 2010. Вып. 8. С. 264-277.

13. Парфентьев Н.П. Творчество книгописцев и художников-знаменщиков братьев Басовых (1580-1630-е гг.) // Вестник Южно-Уральского государственного университета. Сер.: Социально-гуманитарные науки. 2014. Т. 14, № 3. С. 23-48.

14. Парфентьев Н.П. О Строгановской мастерской книжно-рукописного искусства XVIXVII вв. // Вестник Южно-Уральского государственного университета. Сер.: Социальногуманитарные науки. 2008. № 6 (106). С. 43-62.

15. ГИМ. Син. 524. 
16. РГБ. Ф. 173/I. № 137.

17. Клосс Б.М. О происхождении названия «Россия». М., 2012. 152 с.

18. РГАДА. Ф. 237 (Монастырский Приказ). Оп. 1. Ч. 1. № 27. Л. 258 об.

19. РГБ. Ф. 304/I. № 822. Л. 21 об.

20. РГБ. Рум. № 299.

21. Семячко С.A. «Предание старческое новоначальному иноку» в составе Следованной псалтири // Труды Отдела древнерусской литературы. СПб.: Наука, 2014. Т. 62. С. 375-419.

22. СПМЗ. № 274.

23. Парфентьев Н.П. Музыкально-гимнографическое творчество царя Ивана Грозного // Вестник Южно-Уральского государственного университета. Сер.: Социально-гуманитарные науки. 2014. Т. 14, № 1. С. 51-59.

24. РНБ. Сол. № $175 / 175$.

25. РГБ. Ф. 173. № 183.

26. РГБ. Ф. 173/I. № 73.

27. Клосс Б.М. Заметки по истории Троице-Сергиевой лавры XV-XVII вв. // Труды по истории Троице-Сергиевой лавры. СПМЗ. 1998. С. 6-9.

28. РГБ. Ф. 173/I. № 15.

29. РНБ. Сол. № 162/162.

30. РНБ. Сол. № 166/166.

31. ИРЛИ. Карел. № 240.

32. РНБ. Сол. № $700 / 808$.

33. РНБ. Сол. № 704/812.

34. РНБ. Сол. № 59/1425.

35. РНБ. Крыл. № 35.

36. РНБ. Сол. № 587/606.

37. РНБ. Сол. № $1175 / 1285$.

38. ГИМ. Син. 335.

39. РНБ. Сол. № $881 / 991$.

40. Sotheby's. Russian books. The Gospels of Joseph Devochkin. 02 June 2006. URL: http://www.sothebys.com/en/auctions/ecatalogue/2006/russian-books-

106412/lot.119.html\#jumpToLotPopover (дата обращения: 06.08.2016).

41. РНБ. Сол. № 54/54.

Sherstobitova Ekaterina S., South Ural State University (Chelyabinsk, Russian Federation).

E-mail: ekaterina.sherstobitowa@yandex.ru

Tomsk State University Journal of Cultural Studies and Art History, 2018, 31, pp. 272-281.

DOI: $10.17223 / 22220836 / 31 / 28$

\section{GAVRILA (IVAN) BASOV'S LIFE AND ART AS THE MASTER OF MANUSCRIPT ART (THE LAST QUARTER OF THE XVI ${ }^{\text {th }}-$ THE FIRST THIRD OF THE XVII ${ }^{\text {th }}$ CENTURIES)}

Keywords: Old Russian manuscripts; early printed style; Gavrila (Ivan) Basov.

The research is devoted to the issues of an outstanding scriber and the drawing-artist of the last quarter of the XVI ${ }^{\text {th }}$ - the first third of the XVII ${ }^{\text {th }}$ centuries Gavrila, known as Ivan, Basov's life and creativity. Gavrila Basov's art has not been studied before the start of the $21^{\text {st }}$ century. The great interest is connected with the identification of new manuscripts, created by the brothers Stefan, Feodor and Gavrila (Ivan) Basovs, although the first data about the life and artworks of Gavrila was appeared in the $19^{\text {th }}$ century. The article is aimed on systematization and generalization of the information about Gavrila-Ivan Basov.

To date researchers have revealed nine manuscripts, that were created with the participation of the Gavrila in 1585/1586-1630/1631, and researchers attribute several manuscripts to the hand of the master. Gavrila had passed certain stages of developing their talent. Gradually his author's creativity was formed.

Gavrila came from Tver, where he had been formed into a master of books. He copied early printed books. This process was associated with an Early Printed style of an ornamentation. By the mid-1580s. brothers Gavrila, Stefan and Feodor Basovs appeared in Moscow, where they worked for Muscovites. Then Gavrila, probably, returned in Tver. In 1593-1595 Gavrila rewrite the Gospel, where he informed, that he created it in native home. 
In 1608-1631 Gavrila Basov lived at the Trinity-Sergius Monastery. He worked in the scriptorium of the Trinity-Sergius Monastery. This period of the life and creativity became the most striking stage in the development of Gavrila's artistic talent. The ornamentation of created by him manuscripts was different from manner of the book decoration of his brothers Stefan and Feodor.

In the scriptorium of the Trinity-Sergius Monastery Gavrila worked with brother Feodor, scribe Login Shishelov and, possibly, Cyril Novgorodets. Gavrila created manuscripts for outstanding persons of the Trinity-Sergius monastery: the treasurer Joseph Devochkin, the cellarer Abrahamy Palitsyn and the cellarer Alexander Bulatnikov, archimandrite Dionysius Zobninovsky. By 1630-1631 Gavrila took monastic vows, he became recognized as Coenobite Guri.

Gavrila painted head-pieces and initials in the Early Printed style. But by this time decorative variant of the Early Printed style was formed in Gavrila's manuscript art. The ornamentation of the manuscripts was brightness, executed in color and gold. Gavrila depended on the size of books and customers, that is why the changes affected and manner of ornamentation, and the style of the master's letter.

\section{References}

1. Zabelin, I.Ye. (1850) Materialy dlya istorii russkoy ikonopisi [Materials for the history of Russian iconography]. Vremennik Imp. Mosk. Ob-va istorii i drevnostey rossiyskikh. 7.

2. Uspensky, A.I. (1910) Tsarskiye ikonopistsy $i$ zhivopistsy XVII veka [The royal icon painters and painters of the 17th century]. Vol. 2. Moscow: A.I. Snegiryova.

3. Hieromonk Arseny (1873) Istoricheskiye svedeniya ob ikonopisanii v Troitskoy Sergiyevoy Lavre [Historical information on icon painting in the Trinity Lavra of St. Sergius]. In: Filimonov, G.D. (ed.) Sbornik na 1873 g., izdannyy Obshchestvom drevnerusskogo iskusstva pri Moskovskom publichnom muzeye [Collection of 1873, published by the Society of Old Russian Art at the Moscow Public Museum]. Moscow: Katkov \&K. pp. 119-133.

4. Sidorov, A.A. (1951) Drevnerusskaya knizhnaya gravyura [Old Russian book engraving]. Moscow: USSR AS.

5. Budovnits, I.U. (1962) Slovar' russkoy, ukrainskoy, belorusskoy pis'mennosti i literatury do XVIII veka [Dictionary of Russian, Ukrainian, Belarusian writing and literature until the 18th century]. Moscow: USSR AS.

6. The State Historical Museum. Shchuk. 30.

7. The State Historical Museum. Shchuk. 563.

8. The State Historical Museum. Muz. 3441.

9. Dianova, T.V. (1974) Staropechatnyy ornament [Old-print ornament]. In: Pobedova, O.I. Drevnerusskoye iskusstvo [Old Russian Art]. Moscow: USSR AS. pp. 296-334.

10. The State Historical Museum. Sin. 268.

11. Anisimova, T.V. (2006) Rukopisi moskovskikh pistsov brat'yev Basovykh (80-ye gody XVI - nachalo XVII v.) [Manuscripts of the Moscow scribes of the Basov brothers (the 80s of the 16th early 17th centuries)]. In: Fedotova, M.A. (ed.) Ot Srednevekov'ya k Novomu vremeni [From the Middle Ages to the New Time]. Moscow: Indrik. pp. 587-608.

12. Anisimova, T.V. (2010) O novonaydennykh rukopisyakh stroganovskikh pistsov brat'yev Basovykh [On the newly published manuscripts of the Stroganov scribes of the Basov brothers]. In: Matveev, M.Yu. (ed.) Istoriya bibliotek. Issledovaniya, materialy, dokumenty [History of Libraries. Studies, materials, documents]. St. Petersburg: RNL. pp. 264-277.

13. Parfentyev, N.P. (2014a) Tvorchestvo knigopistsev i khudozhnikov-znamenshchikov brat'yev Basovykh (1580-1630-ye gg.) [Creativity of book-writers and artists-denominators the brothers Basov (1580-1630s.)]. Vestnik Yuzhno-ural'skogo gosudarstvennogo universiteta. Ser.: Sotsial'nogumanitarnyye nauki. 14(3). pp. 23-48.

14. Parfentyev, N.P. (2008) O Stroganovskoy masterskoy knizhno-rukopisnogo iskusstva XVIXVII vv. [About Stroganov's workshop of book and hand-written art of the 16th-17th centuries]. Vestnik Yuzhno-Ural'skogo gosudarstvennogo universiteta. Seriya: Sotsial'no-gumanitarnyye nauki. 6(106). pp. 43-62.

15. The State Historical Museum. Sin. 524.

16. Russian State Library. Fund173/I. № 137.

17. Kloss, B.M. (2012) O proiskhozhdenii nazvaniya "Rossiya" [On the origin of the name "Russia"]. Moscow: Rukopisnyye pamyatniki Drevney Rusi.

18. The Russian State Archive of Ancient Acts. Fund 237. List 1. Part 1. № 27.

19. Russian State Library. Fund 304/I. № 822.

20. Russian State Library. Rum. № 299. 
21. Semyachko, S.A. (2014) „Predaniye starcheskoye novonachal'nomu inoku“ v sostave Sledovannoy psaltiri ["Tradition of the Old to the Newly-born Monk" as part of the Psalter]. Trudy Otdela drevnerusskoy literatury. 62. pp. 375-419.

22. Sergiev Posad Museum-Reserve. № 274.

23. Parfentyev, N.P. (2014b) Muzykal'no-gimnograficheskoye tvorchestvo tsarya Ivana Groznogo [Musical-Hymnographic Creativity of the Tsar Ivan the Terrible]. Vestnik Yuzhno-Ural'skogo gosudarstvennogo universiteta. Seriya: Sotsial'no-gumanitarnyye nauki. 14(1). pp. 51-59.

24. Russian National Library. Sol. № 175/175.

25. Russian State Library. Fund 173. № 183.

26. Russian State Library. Fund 173/I. № 73.

27. Kloss, B.M. (1998) Zametki po istorii Troitse-Sergiyevoy lavry XV-XVII vv. [Notes on the history of the Trinity-Sergius Lavra of the 15th - 17th centuries]. In: Manushina, T.N. (ed.) Trudy po istorii Troitse-Sergiyevoy Lavry [Proceedings on the History of the Trinity-St. Sergius Lavra]. Moscow: Podkova. pp. 6-9.

28. Russian State Library. Fund 173/I. № 15.

29. Russian National Library. Sol. № 162/162.

30. Russian National Library. Sol. № 166/166.

31. Institute of Russian Literature. Karel. № 240.

32. Russian National Library. Sol. № 700/808.

33. Russian National Library. Sol. № 704/812.

34. Russian National Library. Sol. № 59/1425.

35. Russian National Library. Kryl. № 35.

36. Russian National Library. Sol. № 587/606.

37. Russian National Library. Sol. № 1175/1285.

38. The State Historical Museum. Sin. 335.

39. Russian National Library. Sol. № 881/991.

40. Sothebys.com. (2006) Sotheby's. Russian books. The Gospels of Joseph Devochkin. 02 June 2006. [Online] Available from: http://www.sothebys.com/en/auctions/ecatalogue/2006/russian-books106412/lot.119.html\#jumpToLotPopover. (Accessed: 6th August 2016).

41. Russian National Library. Sol. № 54/54 